\title{
Proceeding
}

Supplementary Issue: Summer Conferences of Sports Science. Costa Blanca Sports Science Events, 25-26 September 2020. Alicante, Spain.

\section{Study and evaluation of the impacts on the saddle in the L4- L5 and S1 lumbar area during horse riding training session through the use of the last generation inertial sensor}

\author{
RICCARDO IZZO ${ }^{1}$, ALESSANDRA CONVERTINI ${ }^{1}$, TIZIANA D'ISANTO², ANTONIO CEJUDO ${ }^{3}$, CIRO \\ HOSSEINI VARDEI ${ }^{1}$ \\ 1 University of Urbino "Carlo Bo", Italy \\ 2University of Salerno, Italy \\ 3University of Murcia, Spain
}

\begin{abstract}
The aim of this study is to evaluate the extent of the impact and compression of the spine at the lumbosacral level in equestrian sports. In particular, through the use of inertial sensors (IMU) the impacts on the spine that occur during a training session on horseback will be analysed with specifications currently not present in the literature. Pathologies of the spine account for $5-15 \%$ of sports traumatology in horse riding. The study was performed using a K-Track IMU (K-Sport Universal) and the test was carried out by a volunteer, an 18year-old rider (1.78 $\mathrm{mt}$ high, $66.5 \mathrm{~kg}$ weight) who participates in competitions, for each of the three horse gaits were performed 15 measurements on 50 meters long track. The data analysis show, that no impact event greater than $1 \mathrm{~g}$ was detected in the walk, while in the trot as many as 363 events were overrun at an acceleration of $1 \mathrm{~g}$ and 422 in the gallop. The data collected through IMU, highlighted the need for a partial restructuring of the training plan, which would be more adequate as it would contain a more significant number of specific mobilization and strengthening elements of the spine, for a more adequate building of the muscles involved and to better prevent localized trauma.
\end{abstract}

Keywords: Horseback; Spine trauma; Inertial sensors; Corrective methodology.

\section{Cite this article as:}

Izzo, R., Convertini, A., D'Isanto, T., Cejudo, A., \& Vardei, C.H. (2020). Study and evaluation of the impacts on the saddle in the L4-L5 and S1 lumbar area during horse riding training session through the use of the last generation inertial sensor. Journal of Human Sport and Exercise, 15(4proc), S1152-S1159. doi:https://doi.org/10.14198/jhse.2020.15.Proc4.16

Corresponding author. University of Urbino "Carlo Bo", Italy.

E-mail: chosseinivardei@gmail.com

Abstract submitted to: Spring Conferences of Sports Science. Costa Blanca Sports Science Events, 19-20 June 2020. Alicante, Spain.

JOURNAL OF HUMAN SPORT \& EXERCISE ISSN 1988-5202

(c) Faculty of Education. University of Alicante

doi:10.14198/jhse.2020.15.Proc4.16 


\section{INTRODUCTION}

The sport of horse riding is complex, during a single training session, the jockey uses different styles, related to the different horse gaits that are: the walk, the trot, and the gallop. The jockey must adapt and above all continuously correct his posture, in relation to the three basic styles, to adapt to the horse's motion and assume the correct position, using legs as resistance and grip, and uses the upper part of the body, especially the back, which is therefore exposed to continuous shocks and adaptations during all three the styles. In equestrian sports, vertebral pathologies represent the consequences of microtrauma and overload syndrome in which the biomechanical aspects related to the rider's attitude take on a decisive pathogenetic role (Simonetti et al. 1996). Medical radiology researches have studied the biomechanical modifications and traumatic alterations of the spine in equestrian sports, finding important and relevant data by classifying the types of trauma in modifications of the angles and physiological curves of the spine, modifications, and alterations of the interbody discs, modifications on the ligamentous apparatus of the spine and alterations of the somatic components (Olivier et al. 2017). It was found that the average reduction of interbody discs is $33.6 \%$ and that the most compromised discs are L5 and S1. These studies show that low back pain without sciatica irradiation is currently the main clinical symptom in sportsmen who practice horse riding. Given the evidence of this problem in equestrian sports, this study aims to evaluate how many and which impacts occur in a riding session. The study aims to investigate and evaluate the amount and the entity of the impacts in the vertebral column using an inertial measurement unit (IMU) since there are no studies in the literature about this specific argument. Verifying the impacts in the equestrian world will be of fundamental importance to establish precise physical data to be correlated to the problems of the skeletal system to make any corrections to the specific sports training plan, to help the jockey withstand the various load requests and significantly reducing them the risk of trauma. Faber et al. (1999) studied the biomechanics (D'Elia et al 2020, Raiola et al, 2020) of the spine in relation to comparing the vertebral compression using two different types of the saddle the English conventional and the treeless, similar study was updated from Belock et al. (2012), the results show that using the conventional saddle the forces are distributed uniformly. In order to better contextualize the study, it was necessary to study and analyse the biomechanics and the technique of the jockey during the different styles, followed by a brief examination of the main dictates of the classic technique. The two main points to analyse are the alignment of the body on the horse's centre of gravity called the static component and the dynamic component, that is the balance that the jokey must maintain when the horse is in motion. The balance allows the rider to accommodate the undulations of the horse's spine, allowing symmetrical distribution of our weight around the centre of the saddle (Gaibazzi 2015). The position in the saddle depends on the correct distribution of the rider's weight on the horse's back and the absence of unnecessary muscle contractions that would alter the posture and sensitivity of the horse. The fundamental elements for a good position in the saddle are balance, presence of the points of contact between horse and rider, and firmness. The correct neuromuscular recruitment at the elbow, pelvis, knee, and ankle level allows biodynamic cushioning of the horse's locomotion (Olivier at al. 2017). The rider's weight must be directed towards the withers (the highest point of the back; between the collision and the trunk is located in the meeting area between the neck and shoulder blades and serves to measure the height of the animal). Furthermore, it is essential to rest your weight on the ischium and not on the buttocks, this allows a correct weight distribution and aligns the rider to the horse's centre of gravity, this position allows to activate the muscles and remain in the ideal isometric position to be in balance, produce the right strength to lead the horse and decrease the rider's weight on the horse's back (Palmas 1978). The head must be well supported by the atlas and centred on the shoulders, straight and symmetrical, the shoulders are always oriented in the same direction as those of the horse to maintain balance and the direction of movement and the arm drops under its weight, holding the bent forearm that supports the wrist and hand, all in line with the horse's mouth. The spine must maintain physiological curves also through proper specific muscle tension. The use of multi-joint 
movements allows to cushion of the oscillations of the horse's spine in three planes: vertical, horizontal, and sagittal (Gaibazzi 2105). The jockey must support the horse in its movement, and be effective, free from involuntary movements, and have stability thanks to adherence to the horse's trunk and balance on it. The rider's hip and heel should be on an imaginary vertical line, in this position of the leg the rider's calves really feel the body of the horse and therefore provide the aid for the right balancing. A brief description of the three gait styles follows. In the walk the jokey uses his legs alternating them, the hip moves forward when the front leg of the horse touches the ground (Palmas 1978). The trot is a movement of alternating diagonals separated by moments of suspension in a two-beat rhythm. We distinguish three trot steps: ordinary trot, collected trot, and extended trot. The rider places himself slightly in front of the vertical, lifts himself a little from the saddle, and then gently returns to the deepest point of the saddle. The riders' centre of gravity, however, is above that of the horse, during the trot the legs push simultaneously at the exact moment the rider is in the saddle. The gallop is a sequence followed by a moment of suspension with a three-beat rhythm. We distinguish the following steps: ordinary gallop, collected gallop, extended gallop, and false gallop. The horse moves freely with long strides, the rider maintains rhythm and cadence in the saddle and applies pressure with the tailbone, the effect will be to shift the centre of gravity (Palmas 1978). The hypothesis underlying our study is therefore to analyse data through the use of the IMU and define those values in the three investigated styles that unequivocally highlight risks of spinal pathologies connected to the frequent and continuous stress of the lumbar area.

\section{MEANS AND METHOD}

The study addressed is aimed at evaluating the impacts, which occurred during a horse riding training session on the jokey, in an attempt to highlight problems that can affect the lumbar (L4-L5) and sacral (S1) area of the rider during the three different horse gaits. The purpose of our research is to analyse the saddle movements, both of the horse and the rider, above all thanks to an analysis of the posture and the evaluation of the differences in acceleration, related to the impact on the lumbar spine in the three styles. The study was performed using a K-Track (IMU Device, K-Sport Universal, Montecchio, ITA) an instrument that has an accelerometer, a gyroscope, and a 3D magnetometer with an acquisition frequency up to $4000 \mathrm{~Hz}$, but set with a frequency of $100 \mathrm{~Hz}$ (Izzo et al. 2019). The use of inertial sensors chosen for their extreme accuracy in detecting speed, acceleration, and displacement even in external paths, allowed us to measure the acceleration and displacement of the jokey in the three axes to evaluate the posture and the impacts. The IMU must be worn in a specific shirt equipped with a pocket (positioned on the back at the shoulder blad height) designed in order to don't allow unwanted movements to the instrument so as to allow optimal and precise data caption. The idea was to perform a pilot study to test the validity IMU in the evaluation of impacts during the horse riding, only one jokey was analysed, we are aware that the sample doesn't permit to receive a statistical value of the study. The test was carried out by a volunteer, an 18-year-old rider (1.78 mt high, $66.5 \mathrm{~kg}$ weight) who participates in competitions with the FISE (Italian Federation of Equestrian Sports) of the region Marche, the subject during the test did not present any physical disturbances/illness. The athlete was informed of all the investigative protocols and the problems of the case and he agreed to carry out the tests. Furthermore, the study does not present any type of conflict of interest. The test was carried out, in only one day, with one session which lasted 3 hours, from 10 AM to 13 AM with normal climatic conditions in the typical riding ground for horses. The jokey worn the jacket and the IMU was turned on, all the measurement was carried out on a straight track 50 meters long, all the three-horse gait were analysed. Each horse gaits were performed 15 measurements on 50 meters long track; each measurement was taken after a 20 second pause where the subject and the horse were completely in standing position, this method was used in order to isolate and easily recognize every single measurement round and measure their peaks. At the end of each horse gait analysis the IMU was turned off and turned on again to differentiate the styles, all 
data were collected on an Excel sheet and analysed. The data that were collected are acceleration of the horse and jokey from the sagittal plane (z-axis), movement of the jockey's pelvis up and down from his centre of gravity from the frontal plane (y-axis), and consequently the support of the pelvis on the saddle, the $x$-axis from the transverse plane have not been taken into consideration because the balance of the centre of gravity in this axis does not appear to be of high impact for the spine (Figure 1).

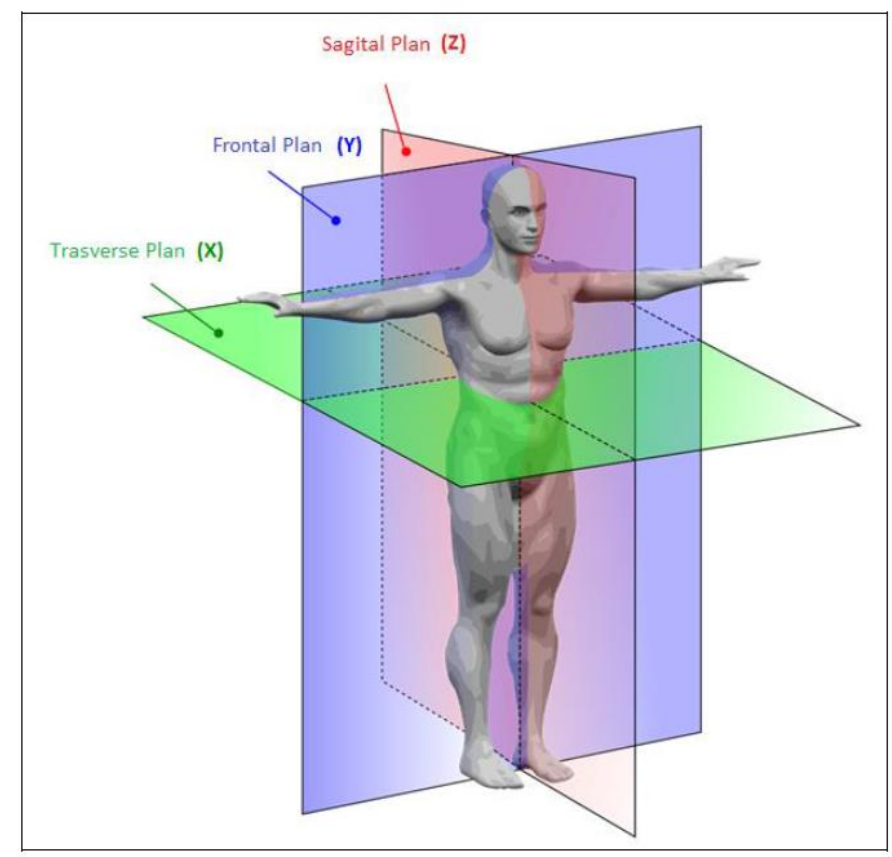

Figure 1. Example of axes and plans in relation to the human body.

Were also analysed the number of events from the acceleration threshold on the y-axis; the value taken into consideration was expressed in gravitational acceleration $(\mathrm{g})$ and the threshold detected were: $>1,>2,>3$, $>4$, and $>5$. Is important to notice that an acceleration of $1 \mathrm{G}$ corresponds to $9.81 \mathrm{~m} / \mathrm{s}^{2}$.

\section{DATA ANALYSIS AND DISCUSSION}

The Figure 2 shows an example of the gait analysis detected from the IMU, the acceleration peaks on the $y$ and z-axis are highlighted and how there is a connection between them, a greater acceleration on the sagittal plane also gives a corresponding negative acceleration on the frontal axis, the latter will be the one that will have a negative effect on the spine. From the figure, it is also easy to highlight the pause phases, which served to divide the measurements.

The analysis of the different accelerations in the three styles has allowed us to establish that there are evident variations in accelerations, this is confirmed by the figures built on the data collected during the tests. A first interesting analyse are the divergences in the accelerations of the three gait styles, especially, therefore, the $z$ accelerations (figures $3,4,5$ ), where it is perfectly possible to notice how the peaks in the three styles are different and therefore there is a considerable difference in the advancement and the thrust in ahead of the horse and this is especially noticeable by a great difference and distance between the peaks. As for the lumbar damage, it can be seen that this is more likely to occur in the trot and the gallop, as can be seen from (figures 4 and 5). The impacts on the saddle more frequent in the gallop then in trot. This detail added to the 
advancement due to acceleration $z$ brings a thrust that is demanding for the lumbar area and could cause progressive traumatic with the risk of injury to the vertebral discs L4-L5 and S1 were the sum of the accelerations and the impact given from the vertical movement of the jokey they meet and create a large load for the column on this area.

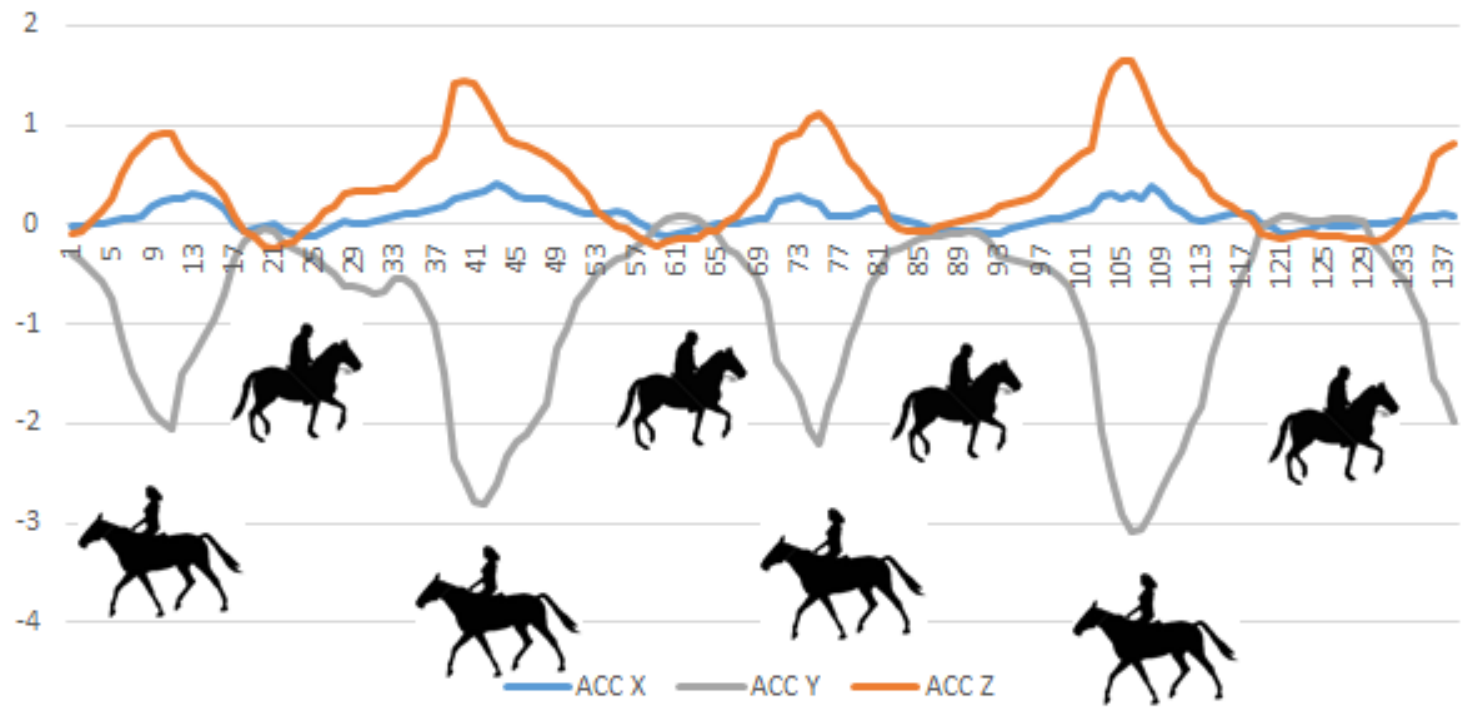

Figure 2. Example of horse gait analysis.

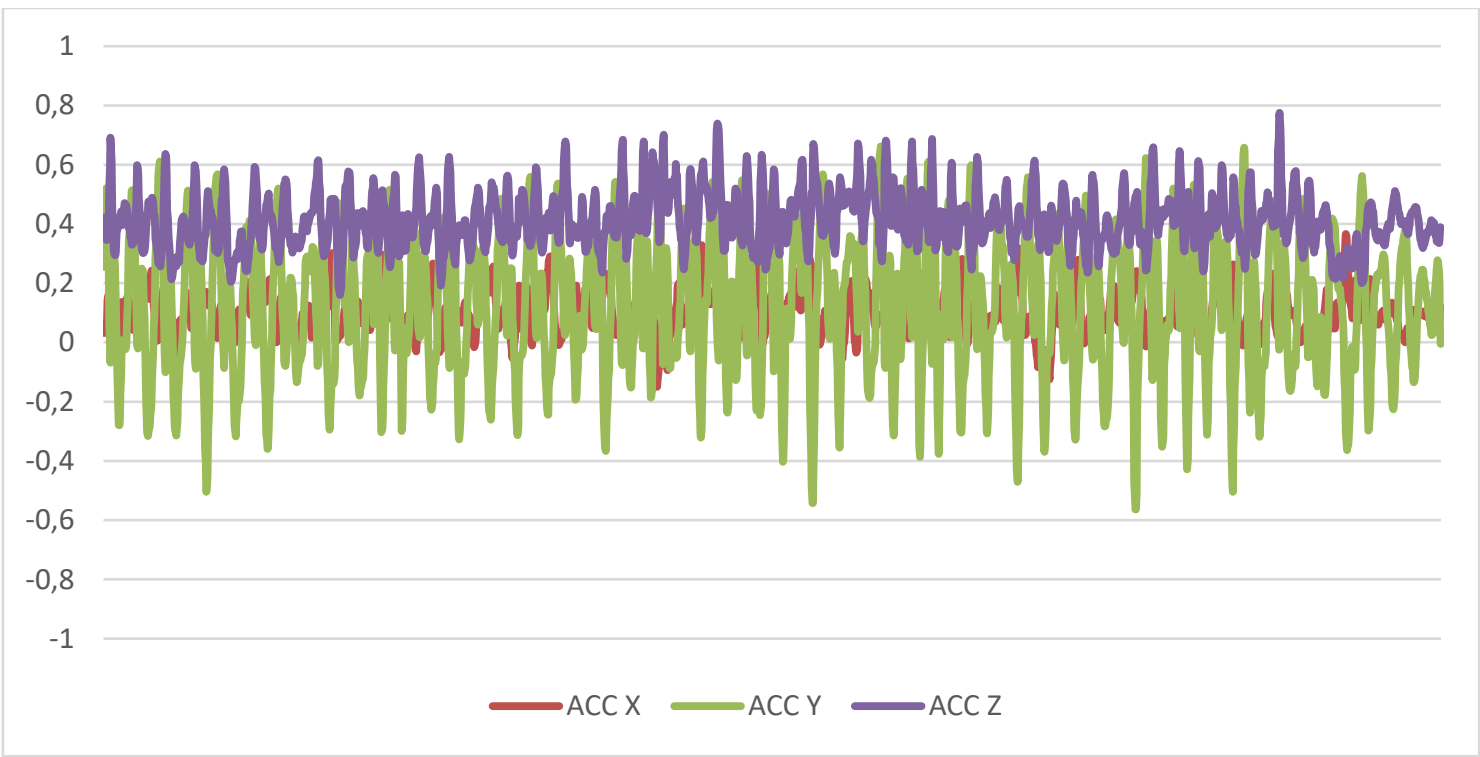

Figure 3. Example of walk. 


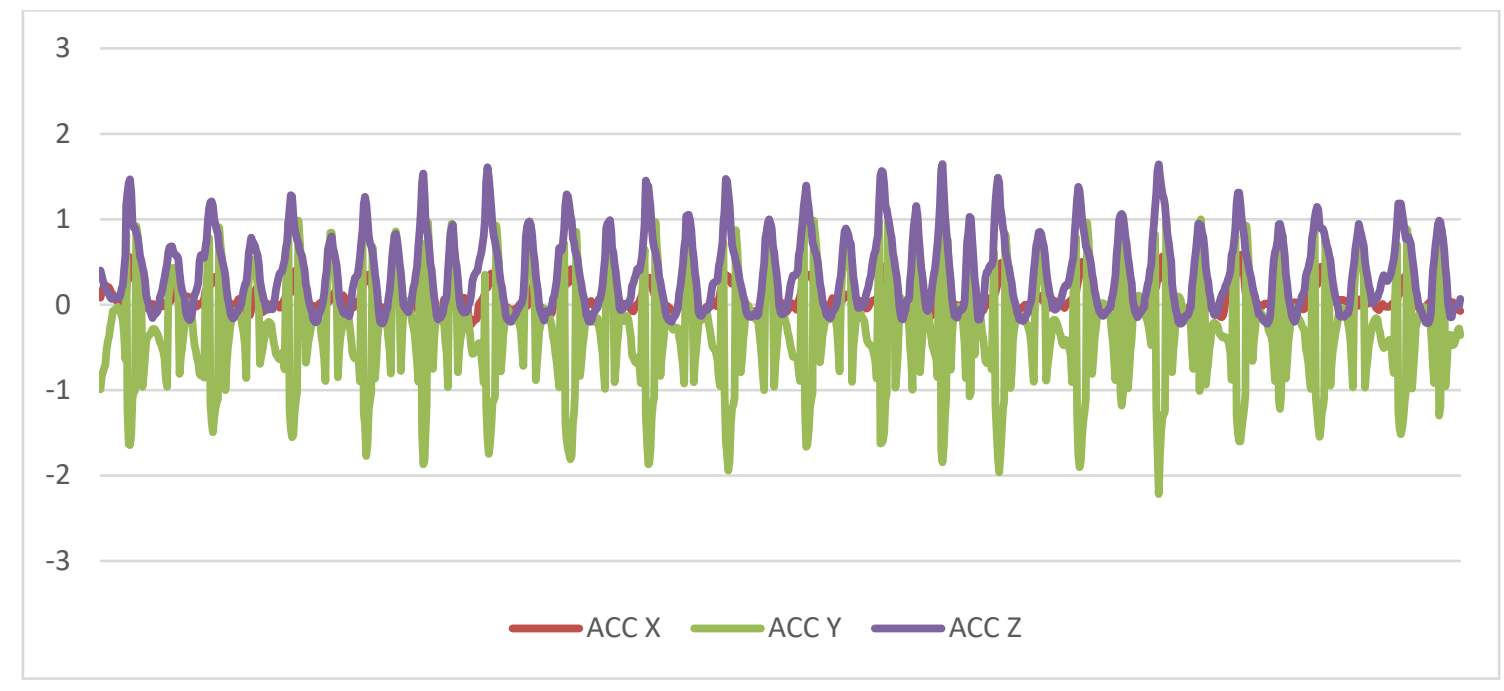

Figure 4. Example of trot.

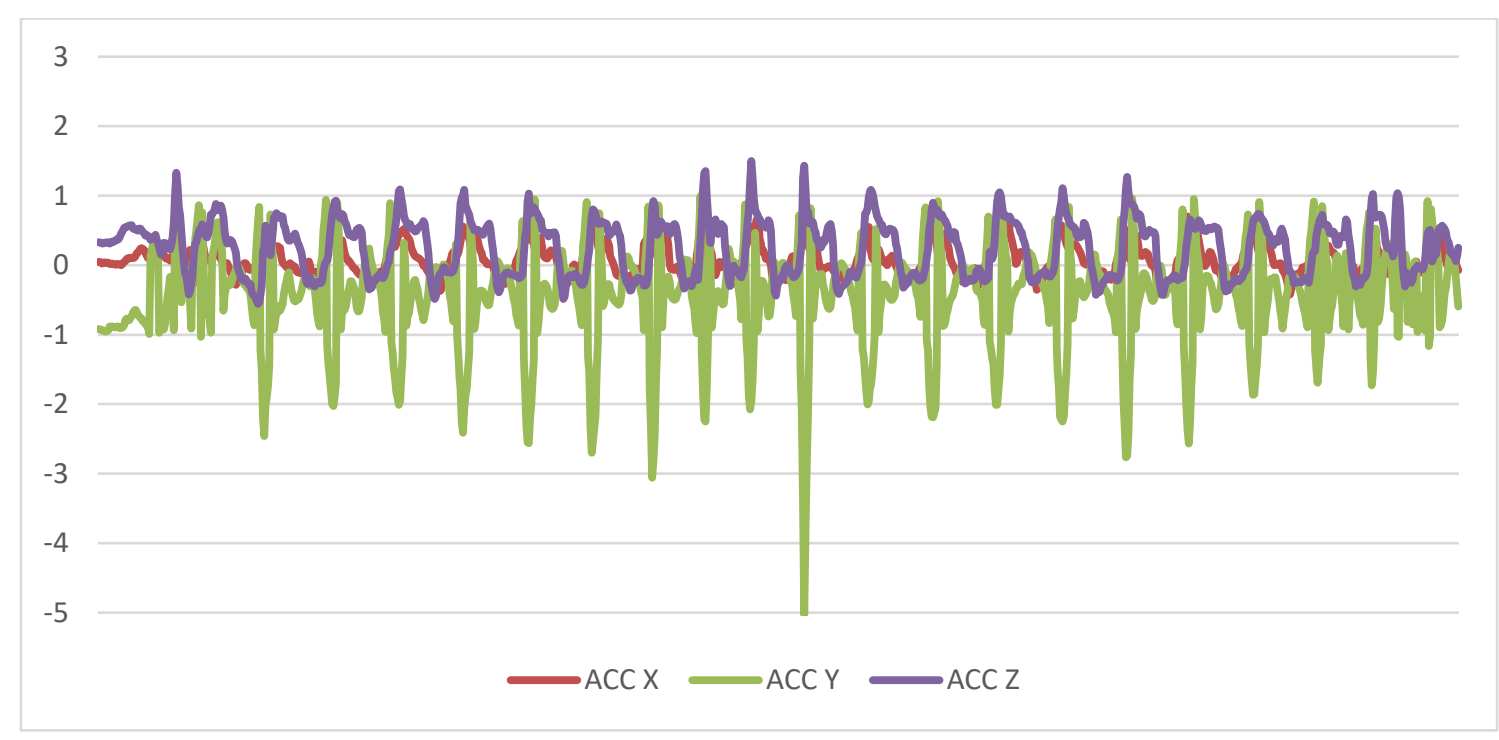

Figure 5. Example of gallop.

The analysis of the figures allows us to evaluate also other details, such as the stylistic trend of the gait, the walk is very dense but without specific peaks, proving to be homogenous and not to present relevant impacts. The trot shows itself as a mix of the other two styles, has a density and a homogeneity, less pronounced, but clearly shows peaks of the trend, a peak towards the z-axis corresponds to a peak of equal intensity towards the $y$-axis which therefore corresponds to the impacts. Talking about the gallop, it shows a less dense trend than the other styles, a soft and long trend of the acceleration of the z-axis corresponds to a sudden peak towards to $y$-axis but of short duration, the extent of the impacts, however, are very high. It is therefore crucial to evaluate the number of accelerative events to determine how much the different styles are stressful at the lumbar level. Table 1 shows data from the number of acceleration events expressed in G; during the walk was not possible to detect value higher than $0.5 \mathrm{G}$, during the trot 311 events were $g>1,51$ events with $g>$ 2 , and 1.3 events with $g>3$ for a total of 363 events, the gallop show 318 events with $g>1,91$ events $g>$ 2,11 events with $g>3,1.4$ with $g>4$ and 0.8 with $g>5$ for a total of 422 events. 
Table 1. Average of acceleration events expressed in $\mathrm{G}$.

\begin{tabular}{lccc}
\hline Accelerations (g) & Walk & Trot & Gallop \\
\hline 1 & 0 & 311 & 318 \\
2 & 0 & 51 & 91 \\
3 & 0 & 1.3 & 11 \\
4 & 0 & 0 & 1.4 \\
5 & 0 & 0 & 0.8 \\
\hline Total & 0 & 363 & 422 \\
\hline
\end{tabular}

\section{CONCLUSION}

The use of IMU in the performance analysis of horse riding permits the detection of the impacts and to assess their relevance and the amount. The data obtained allowed to quantify impacts and eventually prevent jokey spine trauma. It is important to note that not only the maximum acceleration peak but above all the impact volume is the element to be carefully analysed. As for the three styles, no impact event greater than $1 \mathrm{~g}$ was detected in the step, while in the trot as many as 363 events were overrun at an acceleration of $1 \mathrm{~g}$ and 422 in the gallop. Also, accelerations have been recorded for values greater than 2, 3, 4, and $5 \mathrm{~g}$, impact events of this kind have a considerable entity in the lumbar region, as know that an acceleration of $1 \mathrm{G}$ corresponds to $9.81 \mathrm{~m} / \mathrm{s}^{2}$. The high level of accelerations and above all their volume, suggest preventing any spinal trauma of the jokey, through specific core strengthening protocols, focusing on the pelvis and spine stabilizer muscles. Given the findings of the study, significant corrective teaching elements are then suggested in the hypothesized revision of the workload, specifically on the exercises that can be proposed on the preventive side.

\section{REFERENCES}

Simonetti, C., Lupoi, D., Di Giambattista, G., Sessa, V., Rosati, M., Orlacchio, A., (1996). La radiologia medica - Modificazioni biomeccaniche e alterazioni traumatiche del rachide lombo-sacrale negli sport equestri- Radiol Med 1996 edizione Minerva Medica, Torino.

Olivier, A., Faugloire, E., Lejeune, L., Biau, S., \& Isableu, B. (2017). Head Stability and Head-Trunk Coordination in Horseback Riders: The Contribution of Visual Information According to Expertise. Frontiers in human neuroscience, 11, 11. https://doi.org/10.3389/fnhum.2017.00011

D'Elia, F., Di Domenico, F.; D'santo, T.; Altavilla, G., Raiola, G., (2020) From biomechanics to motor learning, Acta Medica Mediterranea, 36 3079. https://doi.org/10.19193/0393-6384_2020_5_473

Raiola, G., Di Domenico, F.; D'Isanto, T.; Altavilla, G., D'Elia, F. (2020) Biomechanics core, Acta Medica Mediterranea, 36 3073. https://doi.org/10.19193/0393-6384_2020_5_474

Faber, M.J, Schamhardt, H.C, Van Weeren, P.R. (1999). Determination of 3D spinal kinematics without defining a local vertebral coordinate system, Journal of Biomechanics, Volume 32, Issue 12, 1999, Pages 1355-1358, ISSN 0021-9290. https://doi.org/10.1016/S0021-9290(99)00131-1

Belock, B., Kaiser, L. J., Lavagnino, M., \& Clayton, H. M. (2012). Comparison of pressure distribution under a conventional saddle and a treeless saddle at sitting trot. Veterinary journal (London, England: 1997), 193(1), 87-91. https://doi.org/10.1016/j.tvjl.2011.11.017

Gaibazzi, G., (2015). Assetto in equitazione - Gruppo Italiano Ecole de Légèreté 2015.

Palmas, A., (1978). Training showjumpers - J.A. Allen.

Izzo, R., Giovannelli, M., Raiola, G. (2019). Training load in elite goalkeepers with K-Track for monitoring performance, Journal of Physical Education and Sport @ (JPES), Vol.19 (Supplement issue 5), Art 
280, pp. 1890-1896, 2019 online ISSN: 2247 - 806X; p-ISSN: 2247 - 8051; ISSN - L = 2247 - 8051 (c) JPES. 